\title{
On the Design and Analysis of Ship Stabilizimg Fin Controller
}

\author{
Ching-Yaw Tzeng \\ Professor, Institute of Maritime Technology, National Taiwan Ocean University, Keelung, Taiwan, R.O.C. \\ Chung-Yi Wu \\ Graduate Student, Institute of Maritime Technology, National Taiwan Ocean University,Keelung, Taiwan, R.O.C.
}

Follow this and additional works at: https://jmstt.ntou.edu.tw/journal

Part of the Engineering Commons

\section{Recommended Citation}

Tzeng, Ching-Yaw and Wu, Chung-Yi (2000) "On the Design and Analysis of Ship Stabilizimg Fin Controller," Journal of Marine Science and Technology. Vol. 8: Iss. 2, Article 7.

DOI: 10.51400/2709-6998.2461

Available at: https://jmstt.ntou.edu.tw/journal/vol8/iss2/7

This Research Article is brought to you for free and open access by Journal of Marine Science and Technology. It has been accepted for inclusion in Journal of Marine Science and Technology by an authorized editor of Journal of Marine Science and Technology. 


\title{
ON THE DESIGN AND ANALYSIS OF SHIP STABILIZING FIN CONTROLLER
}

\author{
Ching-Yaw Tzeng* and Chung-Yi Wu**
}

Keywords: Stabilizing fin, Roll reduction, Internal model control, Sensitivity function, Reference conditioning technique, Notch filter.

\begin{abstract}
A ship stabilizing fin controller based on the Internal Model Control (IMC) method is described in this paper. The proposed method directly shapes the output sensitivity function which relates the wave disturbance to the ship roll motion to achieve good disturbance rejection. The adopted IMC method gives a controller that depends explicitly on the model parameters and a design parameter that specifies the desired system response. Moreover, under the IMC structure, the sensitivity functions depend linearly on the design transfer function and this makes it easy to satisfy the internal stability condition. A reference conditioning technique is employed in the design that takes the limited actuator authority into the controller design consideration to avoid unknowingly pushing the actuator beyond its saturation and slew rate limitation boundaries. Numerical results indicate that very good roll reduction is achieved for sinusoidal disturbance and reasonable roll reduction is obtained for a narrow band type of disturbance generated by passing a white noise sequence through a second order shaping filter.
\end{abstract}

\section{INTRODUCTION}

Stabilization of ship roll motion induced by wave disturbances has received considerable attention. This is because of excessive roll motion would make the crew feel uncomfortable and may also cause damage to the cargoes and equipment on board. Various types of anti-rolling devices are introduced to reduce undesirable wave-induced roll motion [1]. Specifically, bilge keels are the earliest anti-rolling devices in use, which provide extra roll damping to the ship to attenuate the roll motion [2]. Anti-rolling water tanks have been introduced in the early 1900's. Water in the tanks is shifted in response to the wave motion to counteract the

Paper Received July 4, 2000. Author for Correspondence: C. Y. Tzeng. *Professor, Institute of Maritime Technology, National Taiwan Ocean University, Keelung, Taiwan, R.O.C.

**Graduate Student, Institute of Maritime Technology, National Taiwan Ocean University, Keelung, Taiwan, R.O.C. wave- induced roll moments [3].

Stabilizing fins are the most effective and popular anti-rolling devices in use. Stabilizing fins have been used extensively for high speed vessels, particular on war ships and cruise ships. Lift forces are generated by the fins and a couple is produced to counteract the waveinduced roll moment. Since the lift force depends on the relative inflow speed, the stabilizing fins are effective only when the ships are sailing at relatively high speed. Quite some methods have been introduced. Specifically, a multivariable control approach to the design of antirolling fins for a war ship has been proposed, where the rudder and the fins are considered simultaneously to reduce the wave-induced roll motion without sacrificing the yaw control performance [4]. Fuzzy control method basing on empirical if-then rules has also been introduced to the design of the fin stabilization system [5]. Application of the adaptive LQ method to the stabilization for a monohull ship is reported in [6], and an $\mathrm{H}-\infty$ control design method has been employed in the design of a robust stabilizing fin controller [7].

Rudder roll stabilization has gained much interest recently. This is due to its cost effectiveness and saving of space as compared with the conventional stabilizing fin systems and anti-rolling water tanks [8]. However, to achieve effective roll reduction by using the rudder, the rudder rate has to be as high as $10-15 \mathrm{deg} / \mathrm{sec}$, which is considerably faster than most attainable rudder rate aboard ships, where $3 \mathrm{deg} / \mathrm{sec}$ is the typical value [9].

Even though the rudder roll stabilization system has gained much attention recently, the stabilizing fins are still the most effective anti-rolling devices in use [10]. In order to gain good roll reduction performance, the fins have to be moved quickly to counteract the wave-induced roll motion in time. Consequently, saturation (SAT) and slew rate limitation (SRL) are inevitable and they may introduce phase lag and even cause system instability [11].

To maximize the fin stabilization performance, without causing instability to the system, the SAT and SRL have to be taken into design consideration. A reference conditioning technique will be employed that 
modifies the reference input such that the fin command is always equal to the actual input into the plant [12]. This allows full utilization of the limited actuator power, without pushing beyond the saturation and slew rate limitation boundaries unknowingly.

Since the disturbance rejection performance of the stabilizing fin depends on the sensitivity function that reveals the effect of the disturbance on the roll motion of the ship, it is reasonable to directly shape the output sensitivity function under the internal model control (IMC) framework. The IMC design method is characterized by a model-based approach that provides explicit relationship between the structure of the controller and that of the plant model. Moreover, the controller can be conveniently parameterized in terms of a speed of response parameter, which allows the user to tune the controller to meet specific control objective [13]. Numerical simulations with respect to a ship model reported in [14] will be conducted to evaluate the performance of the proposed design method.

\section{SYSTEM DESCRIPTION}

\section{Ship-fin system}

The configuration of the stabilizing fin system is illustrated in Fig. 1. The lift forces $L_{f}$ generated on both fins will result in a stabilizing roll moment $M_{f}$ that counteracts the wave-induced roll moment in order to stabilize the ship.

The transfer function describing the input-output relationship from the fin angle $\alpha$ to the roll angle $\phi$ can be determined from model test data or full scale sea trial data via system identification technique. Specifically, the roll angle-fin transfer function of a ship reported in Ref [14] has been determined

$$
G(s)=\frac{\phi(s)}{\alpha(s)}=\frac{K}{s^{2}+0.06 s+0.1225}
$$

where $K$ is a speed dependent gain coefficient.

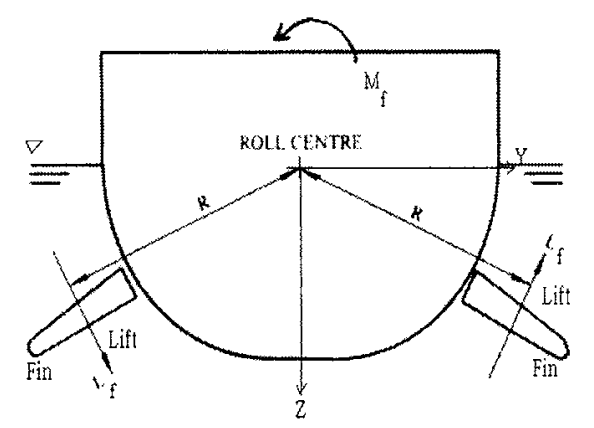

Fig. 1. Ship-fin system.
Specifically, $K=0.461$ for a car ferry at the speed of 11 kts.

\section{Fin saturation and slew rate limitation}

The fin actuators have associated with them two nonlinearities; that is, the saturation (SAT) and slew rate limitation (SRL). The fin angles are assumed to be within $\pm 25 \mathrm{deg}$ and the fin rate limits are within $\pm 20 \mathrm{deg} /$ sec. The fin SAT and SRL are implemented in the structure given in Fig. 2.

The value of $\varepsilon$ in the time lag box can be adjusted to represent the achievable slew rate limitation.

\section{Wave disturbance}

The wave disturbance will be modeled as an output disturbance, which is generated by passing a white noise through a second order shaping filter defined by

$$
H(s)=\frac{K_{w} s}{s^{2}+2 \varsigma \omega_{e} s+\omega_{e}^{2}}
$$

where $K_{w}$ is a coefficient that can be adjusted to represent wave strength effect; $\zeta$ is a damping ratio and $\omega_{e}$ is the encounter frequency. Typically, $\zeta$ is between 0.05 to 0.1 and $\omega_{e}$ is between 0.3 to $1.3 \mathrm{rad} / \mathrm{sec}$ [11]. In the simulation study, $\zeta$ is set to $0.075, \omega_{e}$ is 0.4 and $K_{w}$ is 10 , which result in a narrow band type of disturbance. To a first order approximation, wave motions are linear and the hull response can be obtained as a superposition of the wave induced motion and that created by fin activity. In order to examine the effectiveness of the proposed controller, a pure sinusoidal type of wave disturbance will also be employed in the simulation study.

\section{Fin stabilization system structure}

The anti-rolling fin stabilization system can be represented in the block diagram given in Fig. 3.

The reference signal $\phi_{\text {ref }}$ is set to zero, which indicates the desired stabilized horizontal position. The

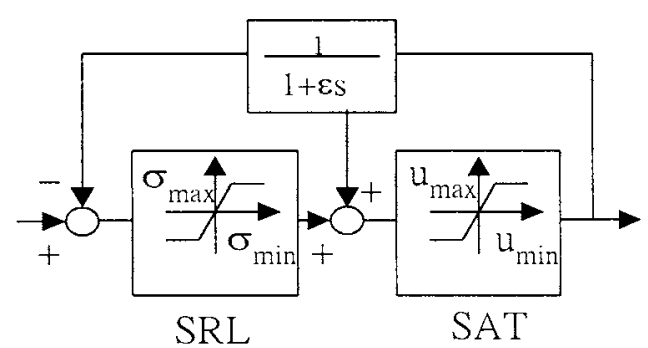

Fig. 2. Fin saturation (SAT) and slew rate limitation (SRL) implementation diagram. 


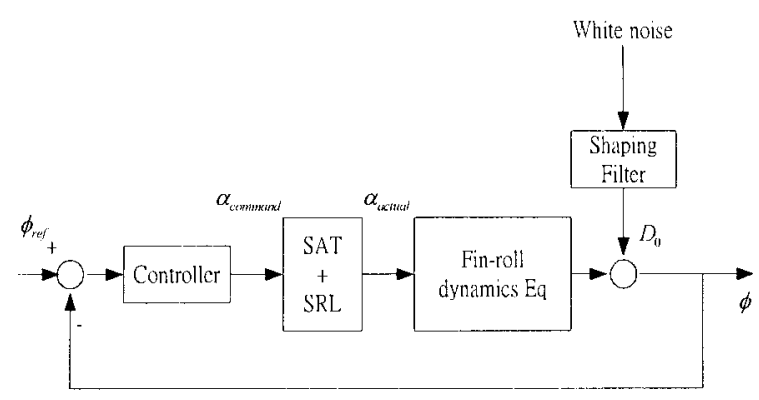

Fig. 3. Fin stabilization system block diagram.

controller $\mathrm{C}$ will be designed with the internal model control (IMC) approach presented in latter section, and the fin SAT and SRL will be directly taken into the design consideration.

\section{INTERNAL MODEL CONTROL (IMC) METHOD}

The IMC design method will be discussed in this section. Specifically, the advantages of IMC method will be highlighted, and the design procedure described.

\section{IMC parameterization}

A block diagram of the IMC structure is shown in Fig. 4A. The IMC and classical feedback structures (see Fig.4B) are equivalent under the following transformations:

$$
\begin{aligned}
& C=\frac{Q}{1-Q \hat{G}} \\
& Q=\frac{C}{1+C \hat{G}}
\end{aligned}
$$

where $C$ is the controller, $G$ is the process being controlled, $\hat{G}$ is the process model, and $\mathrm{Q}$ is a design transfer function. In Figs. 4A-4B, $r$ is the reference input, $\mathrm{y}$ is the output, $\mathrm{u}$ is the control, $d_{i}$ is the input disturbance and $d_{o}$ is the external disturbance. Equivalence between Fig. 4A and Fig. 4B can be readily seen by transforming the dash box to a single block and is represented by the relation shown in Eq. (3a).

The IMC structure shown in Fig. 4A shows that if there are no modelling uncertainties and there is no disturbance, there is no need of feedback. Moreover, the feedback signal in the IMC structure represents uncertainty about the process and the disturbance. Eq. (3a) implies that the controller $C$ is parameterized in terms of the design function $Q$. It also indicates that the controller is directly dependent on the model $\hat{G}$. Hence, the IMC structure can be interpreted as parameteriza-

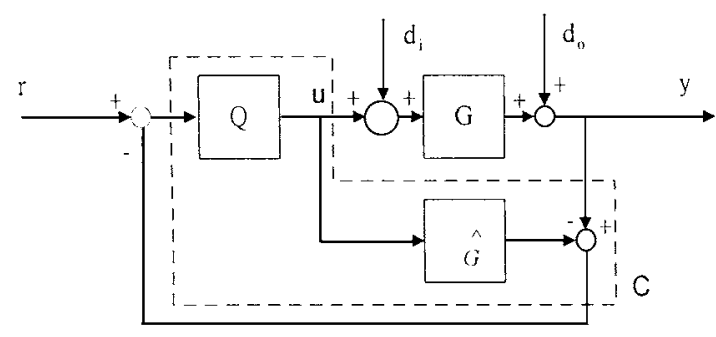

(A)

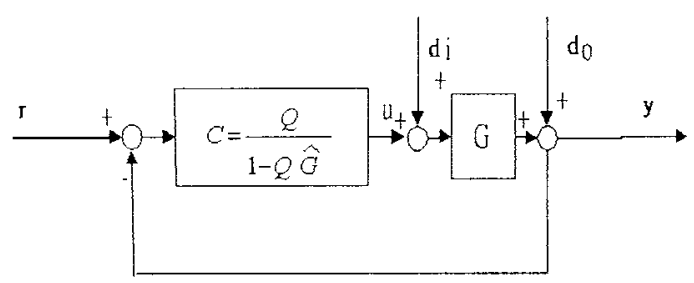

(B)

Fig. 4. (A) IMC structure; (B) Classical feedback structure.

tion of the entire stabilizing controller structure, where the design transfer function $Q$ appears in Eq. (3a) plays the role of the parameter.

\section{IMC design procedure}

In summary, the IMC parameterization design method leads to the following controller:

$$
C=\frac{Q}{1-Q \hat{G}}
$$

where $\hat{G}$ is the process model and $Q$ is a design transfer function defined as

$$
Q=F \hat{G}_{i n v}
$$

where $\hat{G}_{i n v}$ is an approximation to the inverse of the process model $\hat{G}$, and $F$ is a closed-loop specification filter, called, alternatively, the modulating filter, given in the form

$$
F=\frac{1}{(\beta S+1)^{n}}
$$

where $n$ is an integer chosen to make $Q$ bi-proper. That is, the order of the numerator is equal to the order of the denominator, and $\beta$ is a design parameter that characterizes the speed of response of the closed-loop system.

The presence of the term $\hat{G}_{i n v}$ in Eq. (4b) derives from the observation that a controller with the inverse structure of the process being controlled performs perfectly under the ideal case. Specifically, $\hat{G}_{i n v}$ is derived as follows: 


\section{Assume}

$$
\hat{G}(s)=\frac{B_{s}(s) B_{u}(s)}{A_{s}(s) A_{u}(s)}
$$

then

$$
\hat{G}_{i n v}(s)=\frac{A_{s}(s) A_{u}(s)}{\left.B_{s}(s) B_{u}(s)\right|_{s=0}}
$$

where $A_{s}, A_{u}$ represent the stable and unstable poles, respectively, and $B_{s}, B_{u}$ represent the minimum phase and nonminimum phase zeros, respectively. For a nonminimum phase system, direct inversion of the term $B_{u}$ is not allowed; otherwise the stability criterion will be violated. However, it is desirable to extract useful information from the term $B_{u}$ without violating the stability criterion; specially, the DC gain value of $B_{u}$ is the piece of information being retained.

\section{Internal stability}

Referring to the classical feedback structure shown in Fig. 4B, assume that $G=\hat{G}$; that is, the process model exactly describes the process being controlled. Then the corresponding loop is called the nominal loop. It is well known that to ensure internal stability for the nominal loop, the following nominal sensitivity functions have to be stable [13]:

$$
\begin{aligned}
& T=\frac{Y}{R}=\frac{C \hat{G}}{1+C \hat{G}} \\
& S_{o}=\frac{Y}{D_{o}}=\frac{1}{1+C \hat{G}} \\
& S_{i}=\frac{Y}{D_{i}}=\frac{\hat{G}}{1+C \hat{G}} \\
& S_{u}=\frac{U}{R}=\frac{C}{1+C \hat{G}}
\end{aligned}
$$

where $T$ is the nominal complementary sensitivity function, $S_{o}$ is the nominal output sensitivity function, $S_{i}$ is the nominal input sensitivity function and $S_{u}$ is the nominal control sensitivity function. Satisfaction of the stability criterion by the sensitivity functions defined by Eqs. (6) ensures that between any two points in the loop, the input-output relation is stable.

Referring to the IMC structure depicted in Fig. 4A, the sensitivity functions defined by Eqs. (6) can be rewritten in terms of the design transfer function $Q$ and the model $\hat{G}$ as follows:

$$
\begin{aligned}
& T=Q \hat{G} \\
& S_{o}=1-Q \hat{G}
\end{aligned}
$$

$$
\begin{aligned}
& S_{i}=(1-Q \hat{G}) \hat{G} \\
& S_{u}=Q
\end{aligned}
$$

Comparing Eqs. (6) with Eqs. (7), it can be seen that the sensitivity functions are nonlinear in the controller $C$ but are linear in the design transfer function $Q$. The above observation clearly indicates the advantage of the IMC structure over the classical feedback structure in terms of satisfaction of the internal stability criterion. To see this under the IMC structure, given a stable process model $\hat{G}$, internal stability is satisfied by choosing a stable and proper design transfer function $Q$. However, under the classical feedback structure, given a stable process model $\hat{G}$, internal stability is not guaranteed by choosing a stable and proper controller $C$.

\section{SENSITIVITY FUNCTION-BASED APPROACH}

Refer to Fig. 4A, it follows that

$$
Y=T \cdot R+S_{o} \cdot D_{O}+S_{i} \cdot D_{i}
$$

where $Y$ is the system output, $R$ is the reference input, $D_{i}$ and $D_{0}$ are the input and output disturbances. The sensitivity functions $T, S_{o}, S_{i}$ are given by Eqs. (7a)(7c).

Since the purpose of the stabilizing fin control system is to maintain an upright position, the reference input is zero. Moreover, the wave disturbance will be treated as output disturbance. Hence, reduction of the wave-induced rolling motion can be achieved by proper selection of the output sensitivity function $S_{o}$ defined by Eq. (7b). Specifically, a notch filter type of sensitivity function will be selected with the center frequency located near the dominant wave frequency. Select the output sensitivity function $S_{o}$ to have the form of a standard notch filter as

$$
S_{o}(s)=\frac{s^{2}+2 \varsigma^{*} \omega_{n} s+\omega_{n}{ }^{2}}{\left(s+\omega_{n}\right)^{2}}
$$

It follows from Eqs. (4b) and (7b) that the modulating filter $F$ is then given by

$$
F(s)=\frac{2\left(1-\varsigma^{*}\right) \omega_{n} s}{\left(s+\omega_{n}\right)^{2}}
$$

With $F(s)$ given by (10), the corresponding design transfer function $Q$ defined by Eq. (4b) becomes improper. However, in the IMC design, the design transfer function $Q$ is required to be bi-proper. Hence, $F(s)$ can be modified as follows

$$
F(s)=\frac{2\left(1-\varsigma^{*}\right) \omega_{n} s}{\left(s+\omega_{n}\right)^{2}(s+r)}
$$


Then, the corresponding output sensitivity function $S_{o}$ is derived as

$$
S_{o}(s)=\frac{s^{3}+\left(2 \omega_{n}+r\right) s^{2}+\left(2 r+\omega_{n}-2+2 \varsigma^{*}\right) \omega_{n} s+\omega_{n}{ }^{2} r}{s^{3}+\left(2 \omega_{n}+r\right) s^{2}+\left(2 \omega_{n} r+\omega_{n}{ }^{2}\right) s+\omega_{n}{ }^{2} r}
$$

In Eq. (12), the parameters $\omega_{n}, \varsigma^{*}$, and $r$ can be treated as the design parameters that determine the shape of the notch filter. Finally, with respect to the system transfer function given by Eq. (1) the controller can be computed from Eq. (4a) as

$C(s)=\frac{2\left(1-\varsigma^{*}\right) \omega_{n}\left(s^{3}+0.06 s^{2}+0.1225 s\right)}{0.461 \cdot\left[s^{3}+\left(r+2 \omega_{n}\right) s^{2}+\left(2 \varsigma^{*} \omega_{n}+2 \omega_{n} r+\omega_{n}{ }^{2}-2 \omega_{n}\right) s+\omega_{n}{ }^{2} r\right]}$

It is to be noted that the controller given by Eq. (13) is bi-proper. Namely, the order of the numerator is equal to that of the denominator.

\section{REFERENCE CONDITIONING TECHNIQUE}

It is well known that saturation (SAT) and slew rate limitation (SRL) non-linearities of control input to an open-loop stable system may cause performance degradation. Indeed, the system will grow very fast during the saturation and slew rate limitation period and may reach values that are uncontrollable with limited actuator authority [15].

It is certainly possible to design a controller that never reaches the saturation and slew rate limitation bound; however, this will inevitably degrade the performance. In a fin roll stabilization problem, it is desirable to move the fin as quickly as possible to counteract the wave disturbance. Thus, it is necessary to bring the actuator to its saturation and slew rate limitation boundaries in order to achieve the goal.

The reference conditioning technique has been proposed to deal with saturating input for unstable linear systems [16]. In this paper, both the actuator saturation and slew rate limitation are considered [12]. Specifically, the reference input is modified in such a way that the controller states are consistent with actual states of the plant. The control signal never attempts to take on values beyond the bound imposed by the saturation and slew rate limitation, and the linear design properties are preserved.

\section{Fin saturation conditioning}

The configuration of the reference conditioning filter is presented as follows. Given a bi-proper control- ler $C$ described by Eq. (13), it is possible to describe the controller in terms of a strictly proper term and a feedthrough term as follows:

$$
C=C_{0}+C_{1}
$$

where $C_{0}$ is the feedthrough term and $C_{1}$ is the strictly proper term. Let $\phi$ be the actual roll angle and let $R$ be the reference angle. Consider the following control law:

$$
\begin{aligned}
u^{*} & =C(R-\phi) \\
& =C_{0}(R-\phi)+C_{1}(R-\phi)
\end{aligned}
$$

The control input based on Eq. (15) may lead to saturation and slew rate limitation if the actual roll angle $\phi$ is very different from the reference angle $R$. Thus, it is possible to choose a new reference angle to avoid the above condition. Let us assume for this moment there is only saturation limitation. Let Rnew be the modified reference angle, which can be calculated by solving for the following relation:

$$
\begin{aligned}
& C_{1}\left(R_{\text {new }}-\phi\right)+C_{0}\left(R_{\text {new }}-\phi\right) \\
& \quad=\operatorname{SAT}\left[C_{1}\left(R_{\text {new }}-\phi\right)+C_{0}(R-\phi)\right]
\end{aligned}
$$

where $\mathrm{SAT}[\bullet]$ is a saturation function.

Solving Eq. (16) for $R_{\text {new }}$,we have

$$
\begin{aligned}
R_{\text {new }} & =\frac{1}{C_{0}}\left\{S A T\left[C_{1}\left(R_{\text {new }}-\phi\right)-C_{0} \phi+C_{0} R\right]\right. \\
& \left.-\left[C_{1}\left(R_{\text {new }}-\phi\right)-C_{0} \phi\right]\right\}
\end{aligned}
$$

Rearranging Eq. (17), it follows that

$$
R_{\text {new }}=\frac{1}{C_{0}}\left\{S A T\left[u_{1}+C_{0} R\right]-u_{1}\right\}
$$

where

$$
u_{1}=C_{1}\left(R_{n e w}-\phi\right)-C_{0} \phi
$$

Note that the left-hand side (LHS) of Eq. (16) is the actual input into the plant that will not activate the saturation nonlinearity.

Let us call the LHS of Eq. (16) $u$ and write

$$
u=C_{1}\left(R_{\text {new }}-\phi\right)+C_{0}\left(R_{\text {new }}-\phi\right)
$$

Substitution of Eq. (19) into Eq. (20) gives

$$
u=u_{1}+C_{0} R_{\text {new }}
$$

The relationships described by Eqs. (16)-(21) can be realized in terms of the configuration shown in 
Fig. 5.

\section{Fin saturation and slew rate limitation conditioning}

If both saturation and slew rate limitation are considered, Eq. (18) is modified as

$$
R_{\text {new }}=\frac{1}{C_{0}}\left\{(S A T+S R L)\left[u_{1}+C_{0} R\right]-u_{1}\right\}
$$

where $(S A T+S R L)\left[u_{1}+C_{0} R\right]$ implies that both the saturation and slew rate limitation constraints are imposed on the term $u_{1}+C_{0} R$. The conditioning scheme with $S A T$ and $S R L$ constraints is realized with the configuration shown in Fig. 6.

To take into account the presence of SAT and SRL in the system, one would like to 'alert' the controller whenever either one of these nonlinearities is activated. At this point the controller should stop 'pushing', since either the fin reaches its motion limit or its motion rate limit. This is accomplished by passing the control signal through the system presented in the dashed line rectangle shown in Fig. 6.

Summarizing, the control state is now calculated based on the difference between $R_{n e w}$ and $\phi$. This ensures the control state is always consistent with the actual input into the plant. Thus, it is possible to execute the fin roll stabilization very quickly by complying with limited actuator power, without introducing the saturation and slew rate limitation nonlinearities.

\section{NUMERICAL SIMULATIONS}

Recall that for the wave model generated by passing white noise sequence through a shaping filter defined by Eq. (2). In the following computations, the

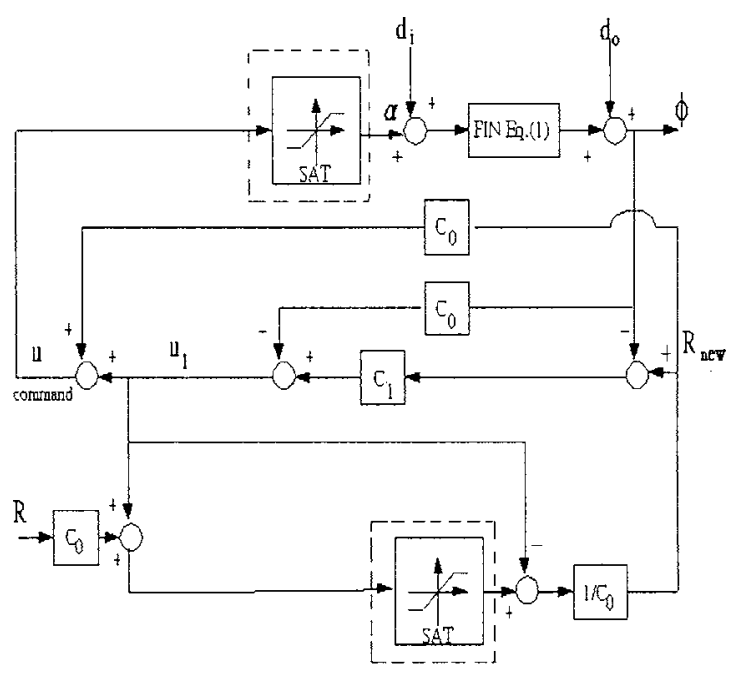

Fig. 5. Controller realization with SAT.

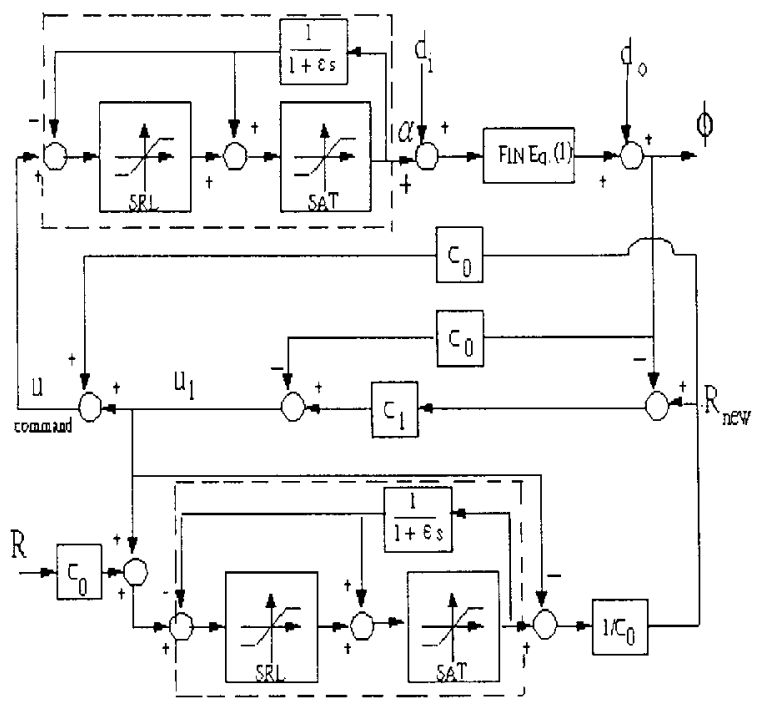

Fig. 6. Controller realization with SAT and SRL.

damping ratio $\zeta$ is set to 0.075 , the encounter frequency $\omega_{e}$ is set to $0.4 \mathrm{rad} / \mathrm{sec}$ and the wave strength factor $K_{w}$ is set to 10 , which will give a wave-induced roll motion within $\pm 15 \mathrm{deg}$. The wave shaping filter employed in the simulation study is then given by

$$
H(s)=\frac{10 s}{s^{2}+0.06 s+0.16}
$$

The design parameters that determine the characteristics of the output sensitivity functions defined by Eq. (12) are selected as follows. Specifically, $\omega_{n}=0.5$, $\varsigma^{*}=-0.25$ and $r=1.15$.

The corresponding output sensitivity function $S_{0}$ of our design is then given by

$$
S_{o}(s)=\frac{s^{3}+2.15 s^{2}+0.15 s+0.2875}{s^{3}+2.15 s^{2}+1.4 s+0.2875}
$$

Finally, the controller $C(s)$ defined by Eq. (13) can be computed as

$$
C(s)=\frac{1.25 s^{3}+0.075 s^{2}+0.1531 s}{0.461 s^{3}+0.989 s^{2}+0.069 s+0.1323}
$$

The Bode plot of the output sensitivity function $S_{0}(s)$ defined by Eq. (24) is shown in Fig. 7. It can be seen that the center frequency of the notch is located near $0.4 \mathrm{rad} / \mathrm{sec}$. Hence, an effective roll reduction can be expected for wave disturbance with dominating frequency around $0.4 \mathrm{rad} / \mathrm{sec}$.

A pure sinusoidal type of disturbance with an amplitude of $15^{\circ}$, frequency of $0.4 \mathrm{rad} / \mathrm{sec}$ is taken as the output disturbance. The stabilized results are given in Fig. 8A and the fin angle employed is given in Fig. 8B. It is clear that for the simple sine wave disturbance, very 


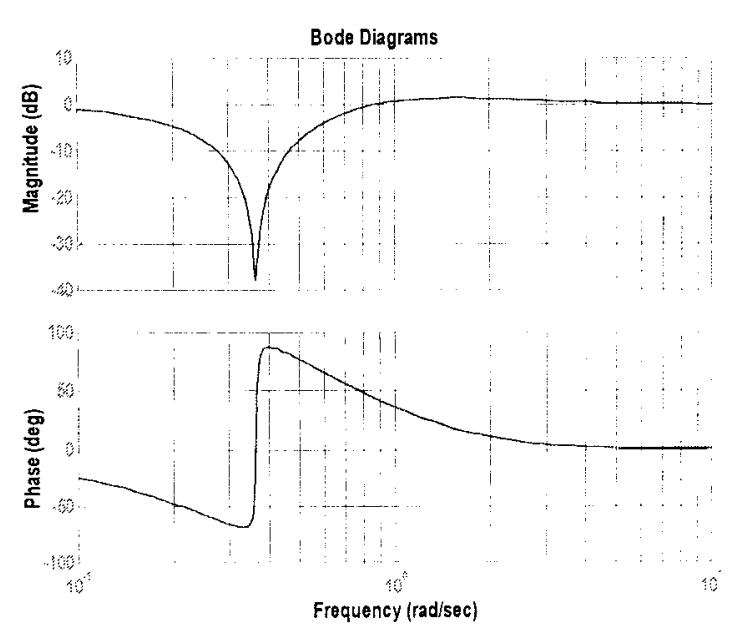

Fig. 7. Bode plot of the output sensitivity function $S_{o}(s)$.

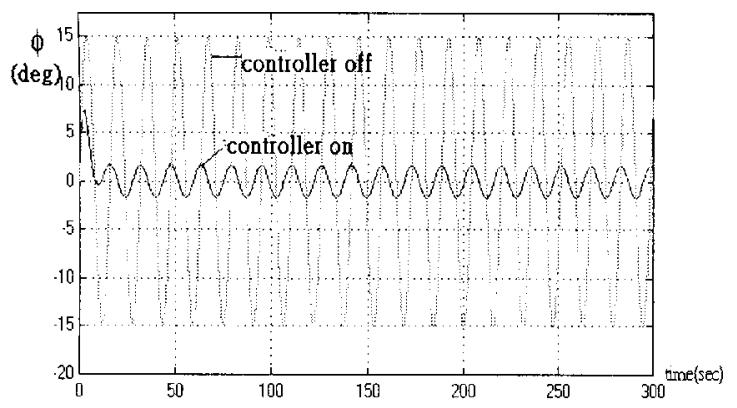

(A)

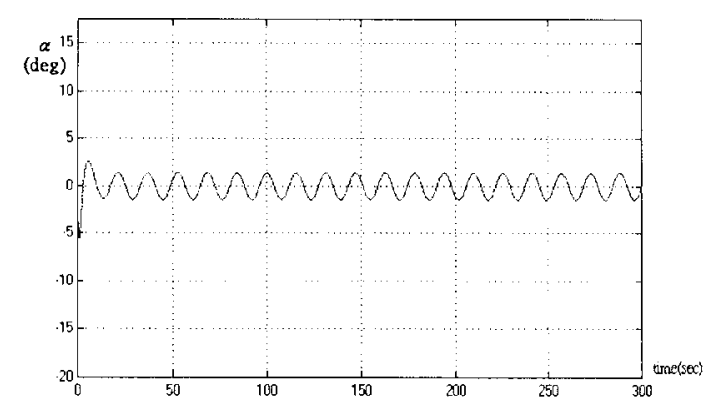

(B)

Fig. 8. (A)Roll reduction for sinusoidal disturbance; (B) Fin angle for sinusoidal disturbance.

good roll reduction is achieved with minimal control effort required. Specifically, the roll motion amplitude is reduced from $15^{\circ}$ to $2^{\circ}$ and the fin angle command is within $\pm 3^{\circ}$.

The more realistic narrow band type of wave disturbance generated by passing a white noise sequence through the shaping filter defined by Eq. (23) is then examined to evaluate the performance of the proposed stabilizing fin controller. Fig. 9A shows the roll angle

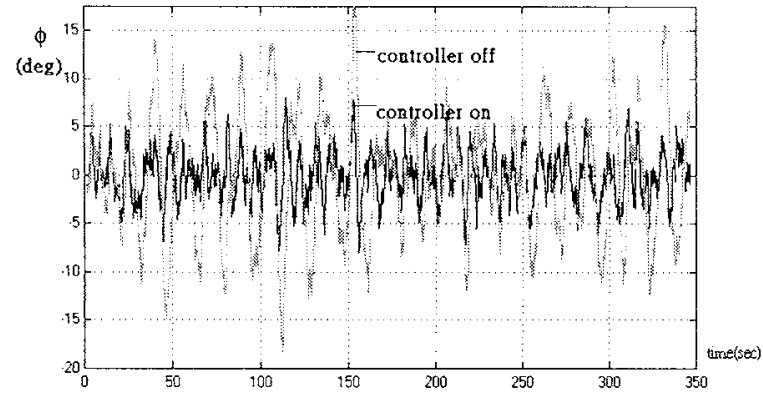

(A)

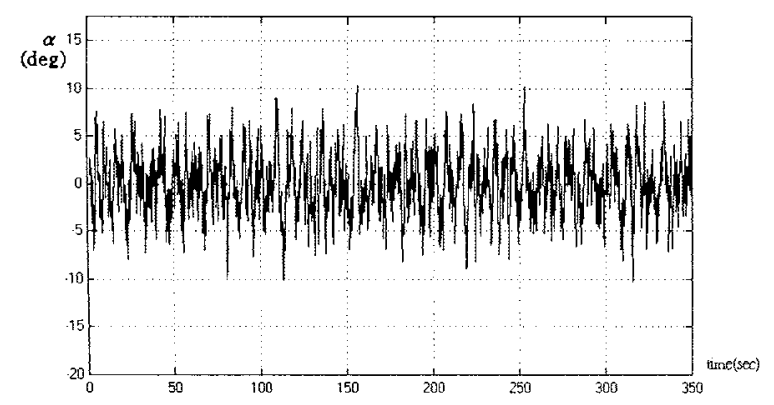

(B)

Fig. 9. (A) Roll reduction for narrow band disturbance; (B) Fin angle for narrow band disturbance.

history with and without the controller and Fig. 9B gives the fin angle time history. It is seen that the roll angle has been reduced from $\pm 15^{\circ}$ to within $\pm 5^{\circ}$ and the fin angle demand is within $\pm 10^{\circ}$. Specifically, the root mean squared (RMS) value of the roll angle has been reduced from $6.7^{\circ}$ to $2.8^{\circ}$ and the RMS value of the fin angle is $3.5^{\circ}$. Moreover, due to the application of the reference conditioning technique, the fin angle employed is within the saturation and slew rate limitation boundaries.

\section{CONCLUSIONS}

An internal model control (IMC) - based stabilizing fin controller design method is found appealing in terms of wave disturbance rejection. Specifically, under the IMC framework, the sensitivity functions depend linearly on the design transfer function $Q$. This makes it straightforward to satisfy the internal stability condition and also allows us to directly shape the output sensitivity function. The proposed modified notch filter type of output sensitivity function is found effective in reducing both the pure sinusoidal wave disturbance and narrow band type of wave disturbance. Due to the ever changing sea state conditions, further research on online estimation of the dominating encounter wave frequency is required and the central frequency of the 
notch filter should be adjusted accordingly to make the proposed controller of practical use.

\section{REFERENCES}

1. Lloyd, A.R.J.M., "Seakeeping: Ship Behavior in Rough Weather," Ellis Horwood Ltd., Chichester, U.K. (1989).

2. Lewis, V.E., Editor, "Principles of Naval Architecture, Vol. III, Motions in Waves and Controllability," the Society of Naval Architects and Marine Engineers, Jersey City, N.J. (1989).

3. Bell, J. and Walker, W.P., "Activated and Passive Controlled Fluid Tank System for Ship Stabilization," Transactions, Society of Naval Architects and Marine Engineers, Vol. 74, pp. 150-193 (1966).

4. Roberts, G.N. and Towill, D.R., "Multivariable Control of Warship Maneuvering," Proceedings, $10^{\text {th }}$ IFAC World Congress, Munich, Germany, pp. 220-225 (1987).

5. Sutton, R., Robert, G.N. and Dearden, S.R., "Design Study of a Fuzzy Controller for Ship Roll Stabilization," Electronics and Communication Engineer Journal, July/August, pp. 159-166 (1989).

6. Fortuna, L. and Muscato, G., “A Roll Stabilization System for a Monohull Ship: Modeling, Identification and Adaptive Control," IEEE Transactions on Control System Technology, Vol. 4, No. 1, pp. 18-28 (1996).

7. Hickney, N.A., Grimble, M.J., Johnson, M., Katebi, R., and Wood, D., "H-infinity Fin Roll Stabilization Control System Design," Proceedings, 3rd IFAC Workshop on Control Applications in Marine System, Trondheim, Norway, pp. 304-311 (1995).

8. Van Amerongen, J. and van Nauta, H.P.," Recent Development in Automatic Steering of Ships," Journal of Navigation, Vol. 39, No. 3, pp. 349-362 (1987).

9. Roberts, G.N.,"A Note on the Applicability of Rudder Roll Stabilization for Ships," Proceedings of the American Control Conference, San Francisco, California, pp. 2403-2407 (1993).

10. Sgobbo, J.N. and Parsons, G., "Rudder/Fin Roll Stabilization to the USCG WMEC 901 Class Vessel, Marine Technology, Vol. 36, No. 3, pp. 157-170 (1999).

11. Fossen, T.I., "Guidance and Control of Ocean
Vehicles," John Wiley and Sons, N.Y., N.Y., (1994).

12. Tzeng, C.Y., Goodwin, G.C and Crisafulli, S, "Internal Model Autopilot Design with Saturating and Slew Rate Limiting Actuator," International Shipbuilding Progress, Vol. 46, No. 448, pp. 401-420 (1999).

13. Morari, M. and Zafiriou, E., "Robust Process Control," Prentice-Hall, Englewood Cliffs, N.J. (1989).

14. Grimble, M.J., "Robust Industrial Control, Optimal Design Approach for Polynominal Systems," Prentice Hall, N.Y., N.Y. (1994).

15. Astrom, K.J. and Wittenmark, B., "Adaptive Control," Addison-Wesley, Reading, Massachusetts (1995).

16. Seron, M., Goodwin, G.C. and Graebe, S.F., "Control System Design Issues for Unstable Linear Systems with Saturating Inputs," IEE Proceedings, Part D, Vol. 142, No. 4, pp. 335-344 (1995).

\section{船舶穞定翼控制器設計與分析 曾 慶 耀吳重 效}

國立臺灣海洋大學航運技術研究所

$$
\text { 摘 要 }
$$

本文利用内模式控制方法, 進行船舶穞定翼控 制器之設計。而穞定翼控制之設計, 基本上爲一千擾 抗拒問題, 其成效則取決於系統之靈敏度函數。由於 在内模式控制架構下, 決定系統内部穞定性之四個靈 敏度函數, 皆爲設計參數之線性函數。因此本文直接 設計合適之靈敏度函數, 以抗拒波浪造成之横搖干 擾, 並同時滿足系統内部穞定性。模擬結果顯示, 選 取具凹槽滤波器形狀之輸出靈敏度函數, 可有效抗拒 正弦波千擾, 以及使用白雜訊通過二階整形滤波器之 窄頻千擾。本文設計之另一特點, 乃將驅動器飽和及 速率飽和效應直接納入控制器之設計考慮, 此可使得 系統在必要時充分利用驅動器有限之馬力, 而不盲目 的下達過大控制命令, 避免了不必要之非線性飽和效 應。 